\title{
STUDIES IN RHEUMATIC DISEASE. V. THE AGE AT ONSET OF PRIMARY RHEUMATIC ATTACK
}

\author{
By ROSS L. GAULD AND FRANCES E. M. READ \\ (From the Cardiac Clinic of the Harriet Lane Home (Department of Pediatrics) of the \\ Johns Hopkins Hospital and the Department of Epidemiology, School of Hygiene \\ and Public Health, Johns Hopkins University, Baltimore)
}

(Received for publication May 29, 1940)

The literature dealing with the age at onset of rheumatic disease is confusing to the reader. There is not only lack of agreement among the various authors with respect to the age at which the disease is most likely to appear, but also the evidence presented in support of the varying conclusions is not convincing ( 1 to 23 ). The published data on this subject are open to criticism because in most instances they have one or more of four main defects:

1. The data are restricted to a consideration of only one of the various manifestations of the disease. Rheumatic disease manifests itself in a variety of forms, and the age selection is by no means similar for all syndromes, so that data which are restricted to a consideration of only one manifestation do not give a true picture of the age selection of the disease as a whole.

2. The data are obtained from the analysis of groups of cases which are, in themselves, age limited. For this reason the age of greatest susceptibility is found by the pediatric clinic to be in childhood, while clinics with an adult clientele report the maximum incidence to be in adult life.

3. The data are based upon the occurrence of acute attacks of the disease without reference to whether the attack represents an onset or a recurrence. Rheumatic disease is generally regarded as a chronic recurrent condition. The age selection of the disease should, therefore, be determined on the basis of the age at which the disease had its onset, and this, with our present diagnostic standards, is in most instances approximated by the age at which it first became clinically manifest.

4. The analysis deals with the age at onset of the disease without reference to the universe from which the cases are drawn. In other words, no consideration is given to the age distribution of the population at risk from which the cases arise.
It is not a simple matter to obtain data on rheumatic disease free from all of the above defects. At the present time no satisfactory data are available relative to the occurrence of the disease in the general population and because this information is lacking the age selection of the disease must be studied in particular groups of individuals. It is difficult to obtain such a group with any certainty that it is not biased in some form. The question of the age selection of the disease is, however, of sufficient importance to merit further investigation. The purpose of this paper is to present and discuss the results of a study of the age susceptibility to rheumatic disease based on certain information collected in the Cardiac Clinic of the Harriet Lane Home.

\section{MATERIAL AND METHODS}

The data upon which this report is based were abstracted from the medical histories of 96 consecutive admissions of white children to the Cardiac Clinic of the Harriet Lane Home because they were suffering from some rheumatic manifestation. These histories include a careful epidemiological study of the immediate families of these children and the families of their parents, so that information is available regarding the occurrence of rheumatic disease in the patients and their siblings, parents, grandparents, uncles and aunts. The children who were admitted to the clinic suffering from the disease, and who were responsible for the inclusion of their respective families in the study, are denominated "index cases" to distinguish them from their relatives who entered the study because of their relationship to these cases. Each index case, therefore, must, by definition, have had an attack of rheumatic disease during childhood. Such is not the case with their relatives who may or may not have had rheumatic disease.

In this study, as in the four preceding ones (24 to 27), an attack of rheumatic disease was defined as either Chorea, Rheumatic Polyarthritis (Rheumatic Fever) or Rheumatic Carditis, or some combination of two or more of these three syndromes.

The following information is available on each of the index cases and their near relatives: (1) 
year of birth, (2) year of onset of first and subsequent attacks of rheumatic disease, (3) year of death, and (4) date of last observation. From these data the age at onset, death or termination of observation can be readily calculated.

There is, therefore, available information with respect to the age at onset of rheumatic disease in two generations of these families. The generation composed of the index cases and their siblings consists of the offspring in 96 families, totalling 442 individuals. This generation is not suitable for study of age selection because the life-experience of its members is not in any sense complete. The mothers, in most instances, have not passed the childbearing age, and at last observation the mean age of the offspring was only 12 years, with very few of its members having reached adult life.

The preceding generation consists of the offspring in 192 families and its members are the parents, uncles and aunts of the index cases. The life-experience of this generation is much more complete; the parents (grandparents of index cases) are past their reproductive period and the mean age of its living members is approximately 40 years. The final picture with respect to rheumatic disease in this generation is not yet complete because most of its members are still living and hence still at risk of developing the disease if they have not already done so. The data are, however, of such a nature that they lend themselves readily to a study of the age selection of this disease.

\section{Composition of the generation composed of the parents, uncles, and aunts of index cases at the time of last observation}

The generation chosen for study consists of the children of the grandparents of the index cases, and there were 984 such offspring recorded in the histories, but on 13 of these individuals the data were so incomplete that it was impossible to include them in the study group which is, therefore, restricted to the 971 parents, uncles and aunts of the index cases about whom the information is reasonably complete. The age distribution of the generation at the time of last observation is shown in Table I.

It will be noted that 838 of the members of this
TABLE I

Age composition at last observation of offspring in 192 families consisting of parents, uncles and aunts of 96 rheumatic index cases (one generation of these families)

\begin{tabular}{c|c|c|c}
\hline Age & $\begin{array}{c}\text { Living } \\
\text { members }\end{array}$ & $\begin{array}{c}\text { Dead } \\
\text { members }\end{array}$ & Total \\
\cline { 2 - 3 } & & 12 & 12 \\
$3-4$ & 2 & 17 & 19 \\
$5-9$ & 16 & 7 & 23 \\
$10-14$ & 45 & 24 & 69 \\
$15-24$ & 179 & 23 & 202 \\
$25-34$ & 340 & 30 & 370 \\
$35-44$ & 202 & 17 & 219 \\
$45-54$ & 54 & 3 & 57 \\
$55+$ & & $(4 ?)$ & 13 \\
Unknown & & 133 & 971 \\
\hline Total known & 838 & & \\
\hline Mean age & 39.7 & & \\
\hline
\end{tabular}

generation were still living at the time of last observation, at which time their mean age was approximately 40 years. It is believed that all living members have been included in this tabulation, but there is much less certainty of the inclusion of all of the deceased members. To check upon the completeness of the recorded deaths among the group, the number of deaths up to 25 years of age was compared with the expected number of deaths at each age out of 971 births on the basis of the U. S. Life Tables of 1901.1 This comparison is shown in Table II.

TABLE II

Reported deaths among 971 parents, uncles and aunts of index cases, with expected number on basis of $1901 \mathrm{U}$. S. Life Tables by age to 25 years

\begin{tabular}{c|c|c|c}
\hline \hline & \multicolumn{2}{|c|}{$\begin{array}{c}\text { Expected deaths based on 1901 } \\
\text { U. S. Life Tables }\end{array}$} & \\
\cline { 2 - 3 } Age & Out of 971 births & $\begin{array}{c}\text { Out of 971 } \\
\text { survivors to } \\
\text { 3 years of age }\end{array}$ & \\
\cline { 2 - 3 } & 120 & & \\
\hline 0 & 28 & & \\
1 & 13 & 9 & 7 \\
2 & 8 & 7 & 5 \\
3 & 6 & 20 & 17 \\
4 & 17 & 13 & 7 \\
$5-9$ & 11 & 19 & 6 \\
$10-14$ & 17 & 29 & 18 \\
$15-19$ & 24 & & \\
$20-24$ & & & \\
\hline
\end{tabular}

It will be seen that in recording the history of the members of this generation no information

1 The earliest birth in this generation was in 1857 and the latest in 1930. The mean and median year of birth was 1898. 
was obtained regarding individuals who died before reaching 3 years of age. Because of this failure to record such individuals it has not been possible to study the occurrence of the disease under 3 years of age. The expected and recorded deaths after the third year agree reasonably well even when allowance is made for the fact that all recorded deaths occurred among 971 survivors to 3 years of age. It is believed, therefore, that the information with respect to the members of this generation is reasonably complete with regard to those who survived the first 3 years of life.

\section{The relative completeness of the final record of this generation at various ages}

The final and complete history of this generation cannot be recorded until all of its members are dead. Each individual contributes his quota of experience to the record at each age of life as he passes in succession from birth to death. Thus the experience of the whole generation will be completed, first for the youngest age groups and subsequently for each successive age period progressing to old age. At the time of last observation each individual in this generation had contributed experience only to the age attained at that time, and each living member is potentially a contributor of experience in the future at all older ages. A greater proportion of persons have, therefore, passed through the experience in the younger than in the older ages. To illustrate this point Table I has been retabulated in Table III to indicate for this generation, at each age period, the number of individuals who have contributed experience up to the time of last observation, and the number of individuals who are potentially contributors in the future.

It will be seen that the final life-experience on the 971 individuals is almost all recorded for the age groups under 25 years. Only 2 individuals can yet contribute experience under 10 years of age, $18(16+2)$ can contribute experience under 15 years of age, and $63(45+16+2)$ are potential contributors under 25 years of age. The uncompleted portion of the final history is, therefore, small, and at these ages the final record on the entire generation is almost all recorded. In the ages above 25 years the data represent a series
TABLE III

Status and age of parents, uncles and aunts at last observation, with tabulation showing number of individuals in each age period in relation to completeness of observation

\begin{tabular}{|c|c|c|c|c|c|}
\hline \multirow{3}{*}{ Age } & \multirow{2}{*}{\multicolumn{2}{|c|}{ Status last observation }} & \multirow{2}{*}{\multicolumn{3}{|c|}{$\begin{array}{l}\text { Number of individuals within } \\
\text { age period with observations }\end{array}$}} \\
\hline & & & & & \\
\hline & Living & Dead & $\begin{array}{l}\text { Com- } \\
\text { pleted* }\end{array}$ & $\begin{array}{l}\text { Partially } \\
\text { completed }\end{array}$ & $\begin{array}{l}\text { Not yet } \\
\text { begunt }\end{array}$ \\
\hline $\begin{array}{c}3-4 \\
5-9 \\
10-14 \\
15-24 \\
25-34 \\
35-44 \\
45-54 \\
55+\end{array}$ & $\begin{array}{r}0 \\
2 \\
16 \\
45 \\
179 \\
340 \\
202 \\
54\end{array}$ & $\begin{array}{r}12 \\
17 \\
7 \\
24 \\
23 \\
30 \\
17 \\
3\end{array}$ & $\begin{array}{l}971 \\
969 \\
953 \\
908 \\
729 \\
389 \\
187 \\
133\end{array}$ & $\begin{array}{r}0 \\
2 \\
16 \\
45 \\
179 \\
340 \\
202 \\
54\end{array}$ & $\begin{array}{r}0 \\
0 \\
2 \\
18 \\
63 \\
242 \\
582 \\
784\end{array}$ \\
\hline
\end{tabular}

* Deaths + living individuals past the upper limit of age period.

† Persons with a possibility of living to the age period; it is not implied that all persons here recorded will live to reach the age period indicated.

of samples of the final record, and these samples form a decreasing proportion of the final picture with increasing age until in the age group over 55 years the experience is complete with respect only to those individuals who have died and hence are no longer able to contribute experience at this age.

Accuracy of data with respect to the age at onset of rheumatic disease obtained by history

The history of rheumatic disease in these families and the age at which the disease first manifested itself were generally obtained from the parents soon after the index cases were admitted to the clinic. Since these histories, with respect to the parents themselves and their siblings (aunts and uncles of the index cases), were obtained in this manner, they are open to errors which are inherent in this means of acquiring information. As noted above, the histories are defective in that they do not include individuals dying under 3 years of age. However, since rheumatic disease is known to be comparatively rare at these ages, this discrepancy does not invalidate the findings for the older ages, because these children, being already dead, were not at risk of developing the disease at older ages. There are two main errors present in the data which might affect their validity. The first of these is due to the fact that the 
informant (usually a parent of the index case) may not only fail to remember illnesses among his siblings but may also forget his own, particularly those which occurred in early life. This can have two effects: (1) Cases which have their onset early in life may not be reported, and (2) a recurrence may be called a first manifestation, which means that it is recorded as occurring at a later age than the actual onset of the disease. The tendency of this error is, therefore, to decrease the number of cases with onset early in life and to increase the number of cases with onset later in life.

The other main error is due to the fact that following the dispersal of the family group by marriage, etc., other members of the family may have developed the disease unknown to the informant. The effect of this error is to reduce the number of cases with onset in adult life. These two errors are inherent in this method of collecting information; their tendency, however, would be to counterbalance each other. In this study, in so far as possible, such errors have been reduced to a minimum. The histories were carefully taken and checked, and about 70 per cent have been verified by hospital records.

\section{The age at onset of rheumatic disease}

The age at onset of rheumatic disease has been defined, for purposes of this study, as the age at which the patient suffered his first attack with one of the three manifestations (Chorea, Polyarthritis, or Carditis). Among the 971 members of this generation upon whom histories were obtained, 132 individuals had definite histories of having some form of the disease, and in 115 of these the age at onset was definitely stated. The remaining 17 were unable to give the age at onset, although the history of the disease was quite definite. This failure to supply complete information was due partly to defective memory on the part of the informant and partly to the fact that in some instances (10 of 17) the disease was discovered as chronic rheumatic carditis without having shown clinical evidence of the acute disease at any time. The 115 in whom the age at onset was known are shown in Table IV by age and type of first acute manifestation. The age at onset by single years of these 115 cases is also shown graphically in Figure 1.
TABLE IV

Age at onset of cases of rheumatic disease occurring among the parents, uncles and aunts (one generation) of index cases

\begin{tabular}{|c|c|c|c|c|c|}
\hline \multirow[b]{2}{*}{ Age } & \multirow[b]{2}{*}{ Total } & \multicolumn{4}{|c|}{ Type of first manifestation* } \\
\hline & & Chorea & $\begin{array}{c}\text { Rheumatic } \\
\text { poly- } \\
\text { arthritis }\end{array}$ & $\begin{array}{l}\text { Rheu- } \\
\text { matic } \\
\text { carditis }\end{array}$ & $\begin{array}{l}\text { Two or } \\
\text { more syn- } \\
\text { dromest }\end{array}$ \\
\hline $\begin{array}{c}4 \text { years } \\
5-9 \\
10-14 \\
15-19 \\
20-24 \\
25-29 \\
30-34 \\
35-44 \\
\text { Unknown }\end{array}$ & $\begin{array}{r}4 \\
20 \\
27 \\
12 \\
12 \\
16 \\
15 \\
9 \\
17\end{array}$ & $\begin{array}{r}1 \\
6 \\
10 \\
1\end{array}$ & $\begin{array}{r}3 \\
11 \\
16 \\
9 \\
10 \\
13 \\
14 \\
5 \\
6\end{array}$ & $\begin{array}{r}1 \\
2 \\
1 \\
2 \\
1 \\
3 \\
10\end{array}$ & $\begin{array}{l}2 \\
1 \\
1 \\
1 \\
1\end{array}$ \\
\hline Total & 132 & 19 & 87 & 20 & 6 \\
\hline
\end{tabular}

* Cases are listed here according to the manifestation on first attack of the disease. The relationship between the type of manifestation on first attack and subsequent manifestations was:

Manifestation on first attack

Chorea . ........... 18 cases

Rheumatic polyarthritis. . 81 cases

Rheumatic carditis...... 10 cases

Showing other types
of manifestations on
subsequent attacks
9 cases
22 cases
none

† The onsets recorded here were:

Two cases of Chorea with Rheumatic Polyarthritis at 5 and 8 years of age.

One case of Chorea with Rheumatic Carditis at 10 years of age.

Three cases of Rheumatic Polyarthritis with Rheumatic Carditis at 24,28 and 40 years of age.

A study of this table and figure indicates that in this generation individuals who developed the disease had their first manifestations at all ages up to 45 years. The onsets occurred most frequently between the ages of 5 and 15 and 25 and 35 years and there were fewer cases who had their first clinical manifestations between 15 and 25 years.

The syndrome by which the disease was first manifested varied with the age at onset. In 20 of the 51 cases whose onset was under 15 years of age the first manifestation of the disease was an attack of chorea, either alone or accompanied by rheumatic polyarthritis or rheumatic carditis, and in only one instance at this age was the first manifestation an attack of rheumatic carditis alone. The cases with onset after their fifteenth year showed a reversal of this picture, only 1 of the 64 cases manifesting itself first as chorea, while 9 appeared first as rheumatic carditis alone. The number of cases whose onset was indicated 


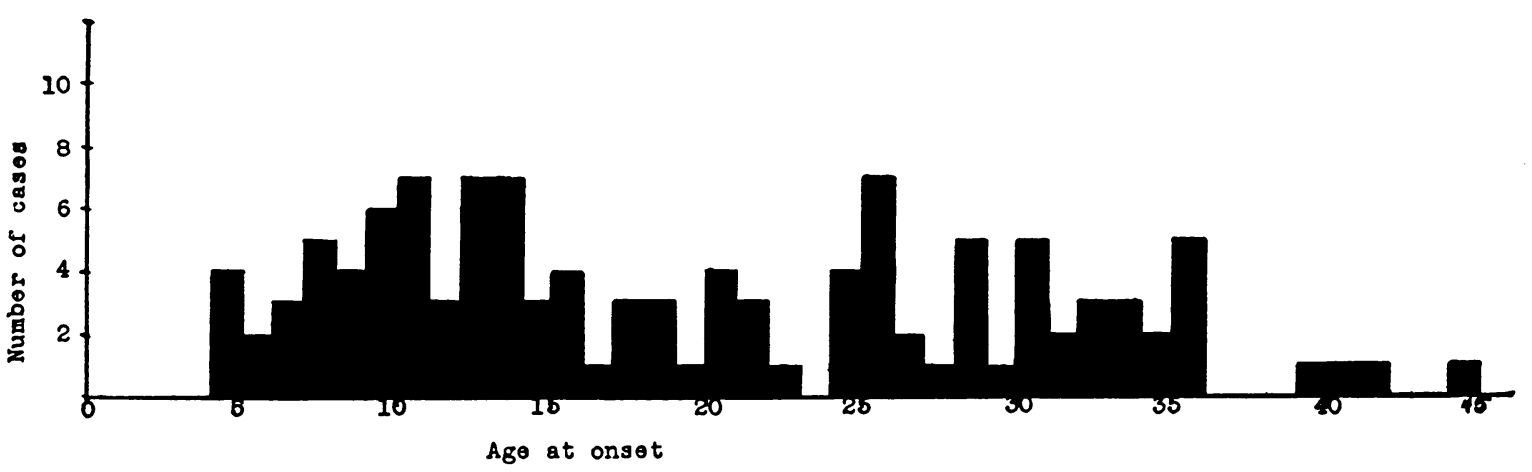

Fig. 1. Age at Onset of Persons with Rheumatic Disease Among Parents, L'icles and Aunts of INDEX CASES

by an attack of rheumatic polyarthritis appeared to be uninfluenced by age.

\section{The age susceptibility of rheumatic disease}

The foregoing analysis has been confined to a consideration of the age at onset of those persons among the members of this generation who have already developed the disease and no consideration has been taken of the fact that all cases of rheumatic disease may not yet have manifested themselves, nor of the number of persons at risk at the various ages from which the cases arose. In order to compare the risk of developing the disease at different ages, it is necessary to consider not only the actual cases which occur, but also the number of persons and the time period during which they were at risk of contracting the disease during each age period. In other words, the cases must be considered in relation to the universe in which they occurred.

The unit which has been used to measure the population at risk during each age period is "person-years at risk" and this unit is defined as 1 person at risk of developing the disease for 1 year. To obtain this population each person was considered at risk from their third birthday and to have remained at risk for a full year at each year of life down to the age at which the first of three possible events occurred: (1) death, (2) onset of rheumatic disease, and (3) termination of observation. At this later age the individual was considered to be at risk for one-half year because the mean time of the occurrence of the event would fall midway between birthdays.

The population at risk, the cases having their
TABLE $\mathrm{v}^{*}$

Showing the population at risk, the cases of rheumatic disease with onsets, and the annual attack rates, by age groups, among one generation (parents, uncles and aunts) of the families of 96 rheumatic index cases

\begin{tabular}{c|c|c|c}
\hline \hline Age & $\begin{array}{c}\text { Population } \\
\text { at risk } \\
\text { (person-years) }\end{array}$ & $\begin{array}{c}\text { Cases of rheu- } \\
\text { matic disease } \\
\text { (onsets) }\end{array}$ & $\begin{array}{c}\text { Annual } \\
\text { rate per } \\
1,000\end{array}$ \\
\hline $3-4$ & $1,890.0$ & 4 & 2.1 \\
$5-9$ & $4,607.5$ & 20 & 4.3 \\
$10-14$ & $4,381.5$ & 27 & 6.2 \\
$15-19$ & $4,209.5$ & 12 & 2.9 \\
$20-24$ & $3,991.0$ & 12 & 3.0 \\
$25-29$ & $3,627.0$ & 16 & 4.4 \\
$30-34$ & $3,129.5$ & 15 & 4.8 \\
$35-44$ & $3,906.5$ & 9 & 2.3 \\
$45+$ & $1,479.5$ & & \\
\hline Total over 2 years & $31,226.0$ & 115 & 3.7 \\
\hline
\end{tabular}

* The 17 cases of rheumatic disease in which the age at onset was unknown have been omitted from this table. The data, therefore, refer to the experience of 954 individuals.

onset, and the annual attack rates are shown, by age groups, in Table $\mathrm{V}$.

It will be noted that for this generation of rheumatic families the mean rate of incidence (onsets) at all ages is 3.7 per 1,000 per year. The risk of manifesting the disease for the first time rose above this mean during two age periods, from 5 to 14 and from 25 to 34 years of age. The incidence was high after the fifth year of life, and reached its maximum from 10 to 14 years of age to be followed by a significant decline during the next decade of life. Between 25 and 34 years of age the incidence was again high, approximating the high rates noted in childhood. Thereafter the incidence declined and no cases are recorded as having their onset after 45 years of age. In interpreting this latter finding it should be re- 
membered that the tabulations with respect to the older ages are based upon only a sample of the final experience of this generation at these ages.

\section{SUMMARY AND CONCLUSION}

Various defects in published data relative to the age selection of rheumatic disease are discussed, and the results of a study on this subject,.in which every effort was made to eliminate these errors, are presented.

The group for study was a generation of the families of 96 consecutive admissions because of rheumatic disease to the Cardiac Clinic of the Harriet Lane Home, and consisted of parents, uncles and aunts of these admissions (index cases).

The accuracy of the data and various possible errors in the histories are recognized and discussed.

The age at onset of 115 cases of rheumatic disease occurring in the generation was found to fall most frequently between the ages of 5 to 14 and 25 to 34 years.

- The relative risk of developing the disease was determined by dividing the number of onsets at each age by the person-years at risk for the corresponding age to obtain an annual incidence rate. This risk was found to be greatest between the ages of 5 to 14 and 25 to 34 years.

Acknowledgment is made to Dr. Kenneth Maxcy for assistance and advice in the preparation of this article.

\section{BIBLIOGRAPHY}

1. Atwater, R. M., Studies in the epidemiology of acute rheumatic fever and related diseases in the United States based on mortality statistics. Am. J. Hyg., $1927,7,343$.

2. Bertram, M., Some features of rheumatic infection. Brit. M. J., 1925, 1, 496.

3. Campbell, M., and Warner, E. C., Study of rheumatic disease in children. Lancet, 1930, 1, 61.

4. Church, W. S., Allbutt and Rolleston System of Medicine. Macmillan and Co., London, 1910.

5. Coombs, C. F., Rheumatic Heart Disease. Wood, New York, 1924.

6. Glover, J. A., Rheumatism from the point of view of central administration. J. Roy. San. Inst., 1938, 59,360 .

7. Hill, N. G., Etiology of juvenile rheumatism. Brit. J. Child. Dis., 1930, 27, 161.
8. Houston, A. N., Analysis of 88 cases of rheumatic fever; comparison with other analyses and discussion. Med. Clin. N. Amer., 1928, 11, 1339.

9. Howard, C. P., and Mills, E. S., Address on acute articular rheumatism and other members of rheumatic cycle. Canad. M. A. J., 1928, 19, 403.

10. Kaiser, A. D., Factors that influence rheumatic disease in children; based on study of 1200 rheumatic children. J. A. M. A., 1934, 103, 886.

11. Lambert, A., Incidence of acute rheumatic fever at Bellevue Hospital. J. A. M. A., 1920, 74, 993.

12. Leonard, M., Puberty and prognosis in rheumatic fever. Am. Heart J., 1937, 14, 192.

13. Mackie, T. T., Rheumatic fever; analytical study of 393 cases of rheumatic fever and 89 cases of chorea. Amer. J. M. Sc., 1926, 172, 199.

14. McSweeney, C. J., Acute rheumatism in childhood. Lancet, 1928, 1, 959.

15. Paul, J. R., Age susceptibility to familial infection in rheumatic fever. J. Clin. Invest., 1931, 10, 53.

16. Poynton, F. J., Cardiac infection in childhood. Brit. M. J., 1918, 1, 417.

17. Riesman, D., Acute rheumatic fever and its variants in childhood and adolescence. J. A. M. A., 1921, 76, 1377.

18. Ritchie, W. T., Rheumatic heart disease-its nature, course and prevention. Tr. Med.-Chir. Soc., Edinburgh, in Edinburgh M. J., 1935, 42, 117.

19. Shapiro, M. J., Natural history of childhood rheumatism in Minnesota. J. Lab. and Clin. Med., 1936, 21, 564.

20. Southey, R., Observations on acute rheumatism. St. Barth. Hosp. Rep., 1878, 14, 1.

21. Swift, H. F., Factors favoring the onset and continuation of rheumatic fever. Am. Heart J., 1930, 6, 625.

22. Wilson, M., Natural history of rheumatic fever in first three decades. J. Pediat., 1937, 10, 456.

23. Wilson, M. G., Lingg, C., and Croxford, G., Statistical studies bearing on problems in classification of heart disease; heart disease in children. Am. Heart J., 1928, 4, 164.

24. Read, F., Ciocco, A., and Taussig, H., The frequency of rheumatic manifestations among siblings, parents, uncles, aunts and grandparents of rheumatic and control patients. Am. J. Hyg., 1938, 27, 719.

25. Gauld, R. L., Ciocco, A., and Read, F., Further observations on the occurrence of rheumatic manifestations in families of rheumatic patients. J. Clin. Invest., 1939, 18, 213.

26. Gauld, R. L., and Read, F., Studies of rheumatic disease. III. Familial association and aggregation in rheumatic disease. J. Clin. Invest., 1940, 19, 393.

27. Read, F., and Gauld, R. L., Studies of rheumatic disease. IV. Familial aggregation of rheumatic disease. Am. J. Hyg., 1940, 31, 124. 